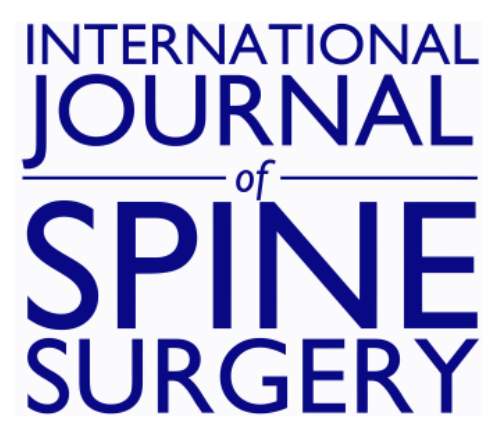

\title{
Ligamentum Flavum Hematoma Presented with Low Back Pain: A Case Report and Review of the Literature
}

FIROOZ SALEHPOUR, FARHAD MIRZAEI, AMIR REZAKHAH, KAMKAR AEINFAR, MOHAMMAD KAZEMZADEH and SEYED AHMAD NASERI ALAVI

Int J Spine Surg 2018, 12 (3) 337-341

doi: https://doi.org/10.14444/5039

http://ijssurgery.com/content/12/3/337

This information is current as of April 25, 2023.

Email Alerts Receive free email-alerts when new articles cite this article. Sign up at: http://ijssurgery.com/alerts 


\title{
Ligamentum Flavum Hematoma Presented with Low Back Pain: A Case Report and Review of the Literature
}

\author{
FIROOZ SALEHPOUR, MD, FARHAD MIRZAEI, MD, AMIR REZAKHAH, MD, KAMKAR AEINFAR, \\ MD, MOHAMMAD KAZEMZADEH, MD, SEYED AHMAD NASERI ALAVI, MD \\ Department of Neurosurgery, Faculty of Medicine, Tabriz University of Medical Sciences, Tabriz, Iran
}

\begin{abstract}
A 61-year-old woman with no past medical history presented with low back pain and radicular pain in the right lower extremity. Magnetic resonance imaging of the lumbar spine showed a heterogeneous intensity mass in the lateral recess of the spinal canal at the L4-5 disk level. Postoperatively, her radicular pain resolved within a few days with excellent low back pain relief. Ligamentum flavum hematoma is a rare differential diagnosis for cystic lesions in the lumbar spine that can be removed simply by surgery with excellent relief of symptoms and improvement in strength of the right lower extremity and increased sensitivity.

Research Article

Keywords: ligamentum flavum, hematoma, lumbar spine, low back pain
\end{abstract}

\section{INTRODUCTION}

Ligamentum flavum hematoma (LFH) is one of the rare causes of radiculopathy and low back pain. Actually, the manifestation of symptoms is similar to that caused by disk herniation and occurs mostly in the lumbar and lower thoracic spine. ${ }^{1}$ The exact mechanism of LFH is not clear, but surgical removal of the hematoma provides excellent results. ${ }^{2,3}$ Most of the cases that have been reported are male. ${ }^{4}$ This study report is a rare case of LFH presenting with radiculopathy of the right leg and low back pain that underwent total laminectomy and removal of hematoma at the L4-5 disk level.

\section{CASE REPORT}

A 61-year-old woman with no past medical history who had been suffering from mild low back pain for 3 months presented with progression of symptoms and pain radiating to the right lower extremity for the past 4 weeks. She had no history of previous trauma, lumbar spine surgery, or anticoagulant therapy. She also had no medical illness, such as diabetes mellitus, hypertension, or other cardiac disease. All laboratory data, including coagulative tests, were normal and excluded bleeding tendency in the patient. On physical examination, she had tenderness in the paraspinal region at the level of the lower lumbar spine. Deep tendon reflexes in the lower extremities and bowel and bladder function were normal. The straight leg raising test was positive at 45 degrees on the right side. Also, neurological examination found fourfifths strength in the lower distal extremity of the right side and hyperesthesia in the right L4 and L5 sensory distributions. Lateral radiography of lumbar spine in flexion-extension showed no significant instability except mild spondylotic changes (Figure 1). Magnetic resonance imaging (MRI) revealed spinal cord compression at the L4-5 level caused by a postrolateral mass that was contiguous with the ligamentum flavum on the right side (Figure 2). Ligamentum flavum was obviously hypertrophic. The mass lesion appeared as an area of heterogeneous signal intensity on both T1-weighted and T2weighted images. Contrast-enhanced MRI images were not obtained. Because of continuous low back and radicular pain, surgical treatment was indicated. The patient underwent a L4-5 laminectomy for decompression of the spinal canal and resection of the lesion. Easy aspiration of brownish fluid, suggesting an old hematoma, was done, and the remaining thickened ligamentum flavum was completely removed. The intraoperative diagnosis was LFH in the lumbar spine, and histological examination of the specimen confirmed our diagnosis (Figures 3 and 4). In the postoperative course, the patient's low back pain and radiculopathy resolved 


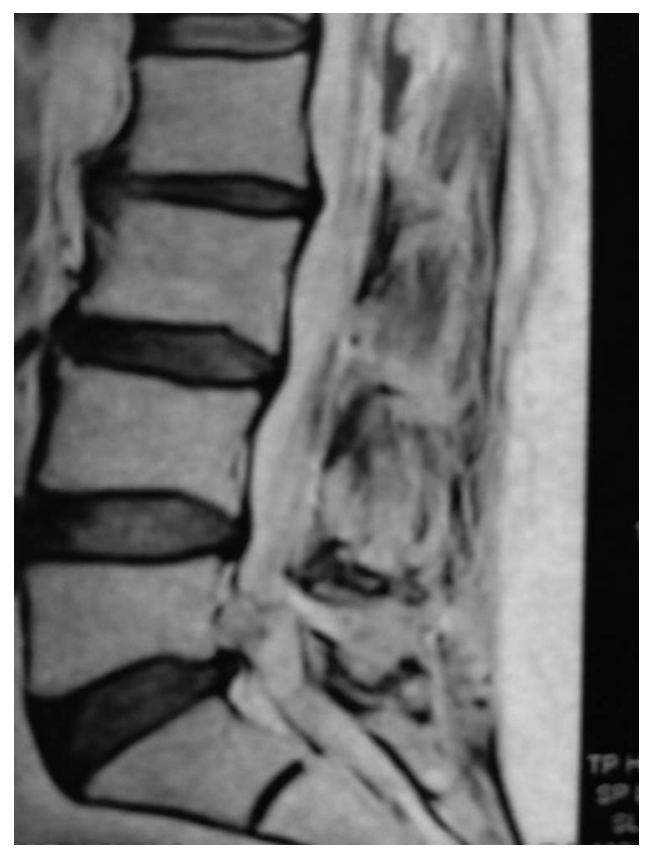

Figure 1. Lateral radiography of lumbar spine in flexion-extension. There was no significant instability.

completely within a few days after the operation. Postoperation T2-weighted MRI confirmed that (Figure 5). She also experienced improvement in strength of the right lower extremity and increased sensitivity. The patient was discharged without any neurological deficit, and at 4 weeks after surgery follow-up, the patient remained asymptomatic.

\section{DISCUSSION}

Ligamentum flavum are long ligamentous structures in humans that are extended from the second cervical up to the lumbosacral vertebra. They

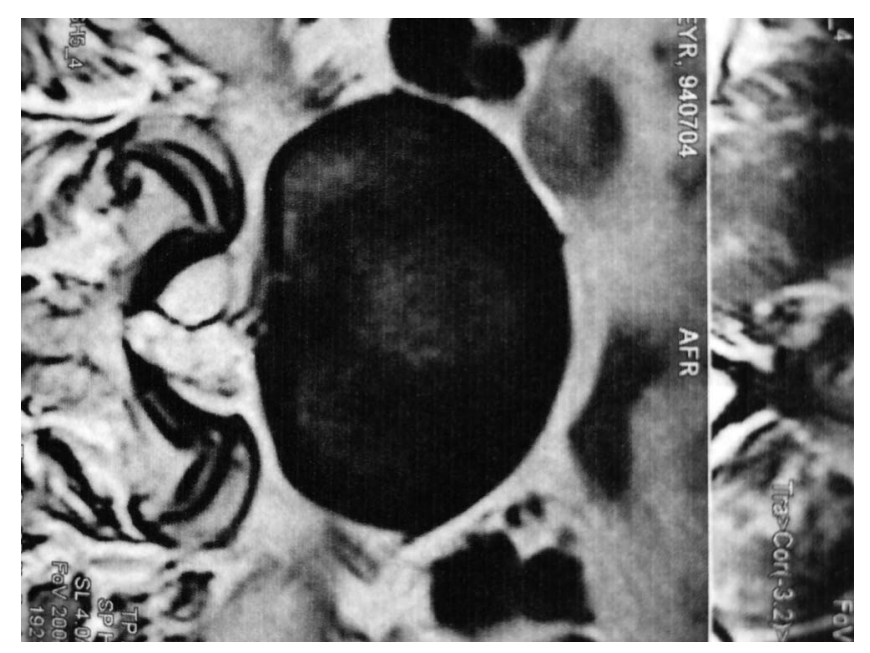

Figure 2. Magnetic resonance imaging shows spinal cord compression at the L4/L5 level and also ligamentum flavum on the right side.

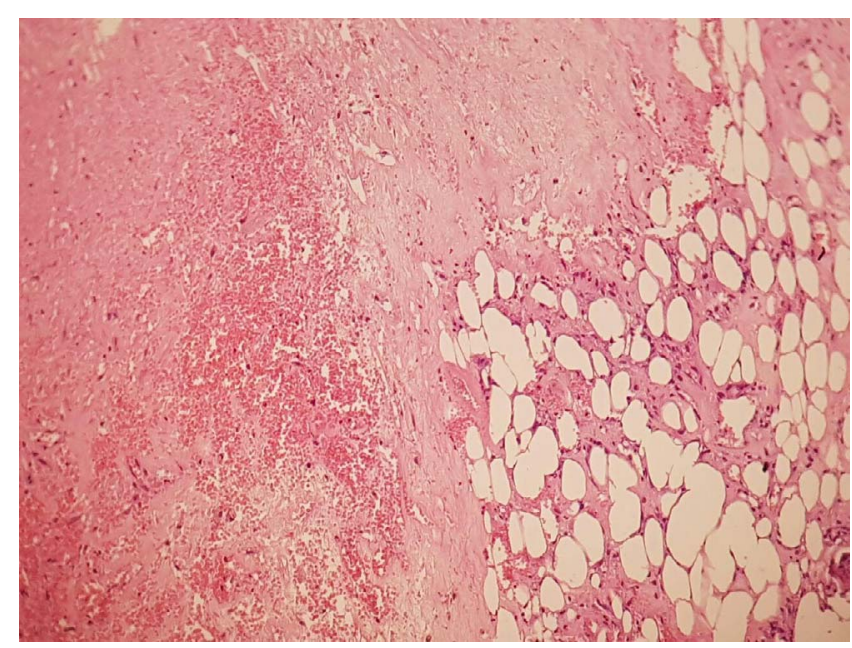

Figure 3. Histological examination of the specimen confirms ligamentum flavum hematoma.

consist of $80 \%$ elastic fibers and $20 \%$ collagen and have an assistive role in the maintenance of an erect posture. Ligamentum flavum are poorly vascularized, and only a few small vessels pass through it. Therefore, intraligamentous bleeding very rarely happens; distinguishing hematoma from other diseases, such as ganglion, synovial cyst, disk herniation, or neoplasm, can be difficult ${ }^{5}$ For preoperative diagnosis of LFH, MRI imaging is the most preferred method, showing the heterogeneous intensity of the mass lesion continuous with ligamentum flavum. The mechanism of disease is still unclear, but vessel rupture within the ligamentum flavum or hemorrhage from the degenerative facet joint may be the cause of hematoma ${ }^{4}$ Analysis of the previously reported cases of LFH showed these characteristics: The most commonly affected

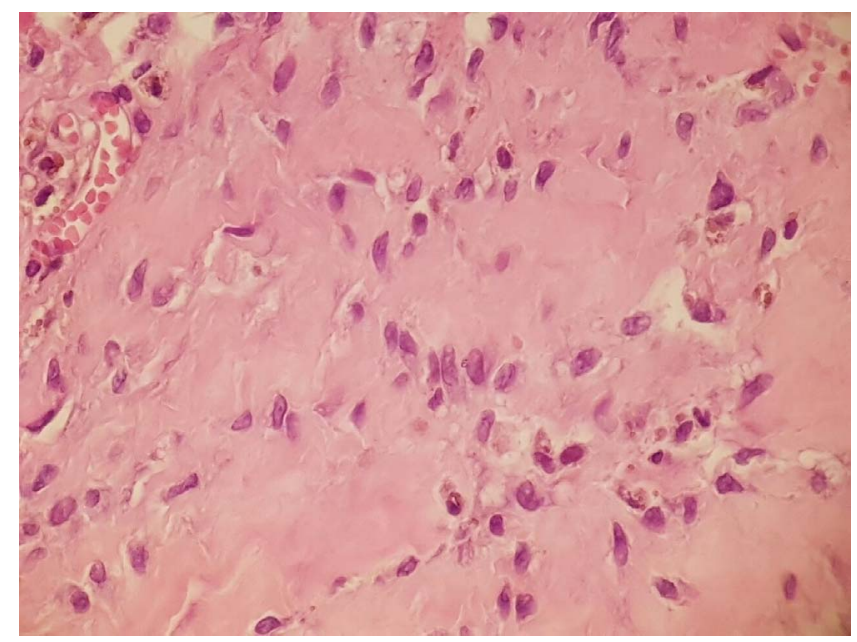

Figure 4. Histological examination of the specimen confirms ligamentum flavum hematoma. 
Salehpour et al.

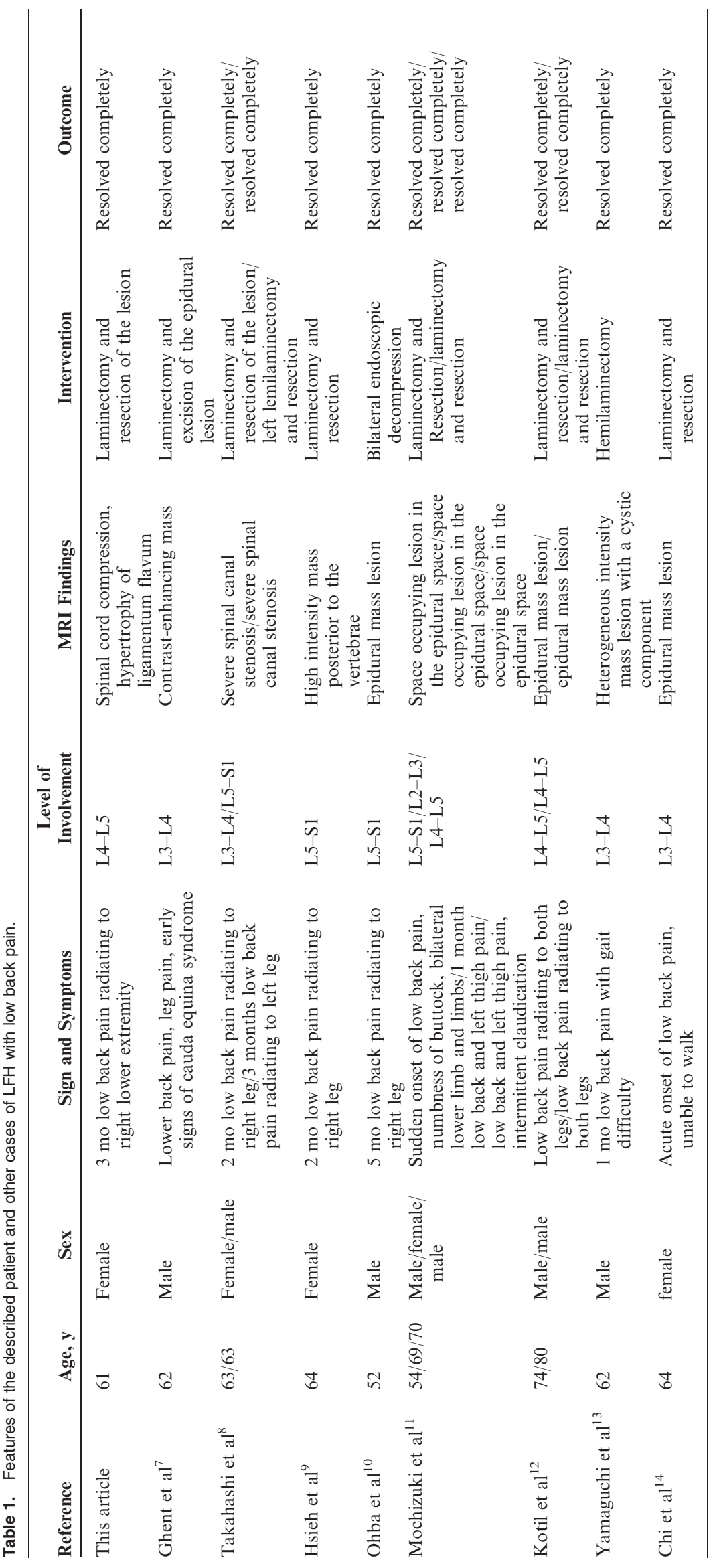




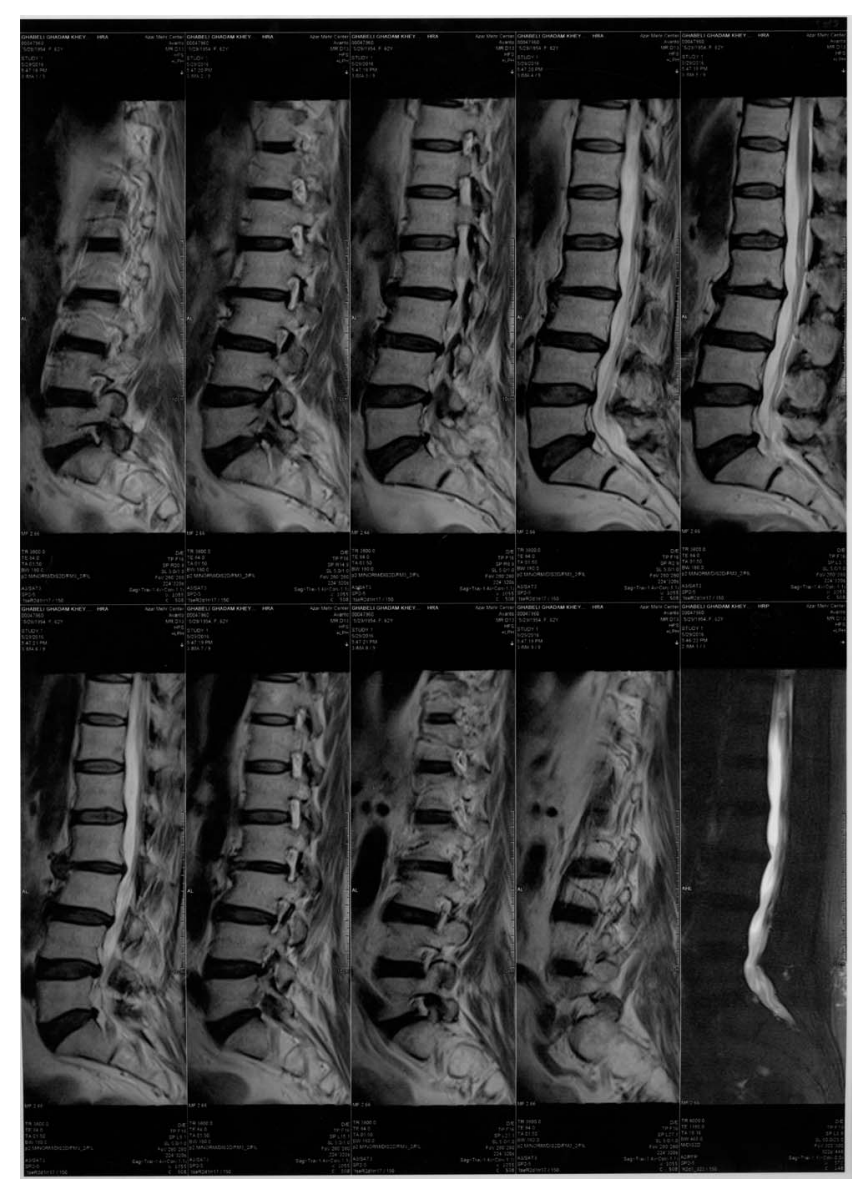

Figure 5. Postoperation T2-weighted magnetic resonance imaging shows no sign.

part in the spine is the lumbar area. The disease is caused mostly by minor trauma during normal activities. Most patients are middle aged or elderly males, and the disease commonly happens only at a single level, although involvement of more than one level has also been reported. ${ }^{4}$ In most patients, the clinical course progressively worsens. The treatment of choice for LFH is surgical removal of the lesion if progressive neurological symptoms occur. The analysis of reported cases also showed that total surgical resection of the mass lesion is an effective treatment for patients with $\mathrm{LFH}^{2,3}$ Since LFH has no attachment to the facet joints, the stability of the lumbar spine can be regarded as intact, so simple microsurgical laminectomy provides an adequate operative view to remove the hematoma of ligamentum flavum, and in most cases additional fixation is unnecessary ${ }^{6} \mathrm{We}$ identified all the studies on LFH in patients with low back pain by a systematic search and hand search of the literature and electronic databases, including Google scholar, MEDLINE, and EMBASE for studies published until June 2016. The search term was "Ligament Flavum Hematoma” OR "LFH," AND “Low back pain" OR "Lumbar spine." The search resulted in 9 case reports of LFH with low back pain. Of the 13 cases of LFH who presented with low back pain, 9 were male, and 4 were female. The maximum age of presentation was 80 years, and the minimum age

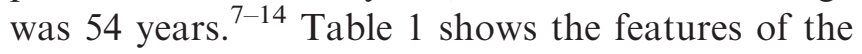
described patient and the other cases of LFH with low back pain. This presented case of LFH in the lumbar spine was completely cured by total resection of the mass lesion through L4-5 laminectomy and relieved the patient's symptoms of low back pain and radiculopathy.

\section{CONCLUSION}

LFH is a rare cause of spinal root and canal compression that can be removed simply through surgery with excellent relief of symptoms. Low back pain occurs more in male in patients with LFH than in female patients. LFH is a rare differential diagnosis for cystic lesions in the lumbar spine.

\section{REFERENCES}

1. Minamide A, Yashodia M, Tamaki T, Nastumi K. Ligamentum flavum hematoma in the lumbar spine. J Orthop Sci. 1999;4(5):376-379.

2. Cruz-Cone R, Berjano P, Buitron Z. Ligamentum flavum hematoma presenting as progressive root compression in the lumbar spine. Spine. 1995;20(13):1506-1509.

3. Hirawaka K, Hanakita J, Suwa H, Matsushita N, Oda M, Muro H, Fukushima T. A post-traumatic ligamentum flavum progressive hematoma. Spine (Phila Pa 1976). 2000;25(9):1182-1184.

4. Mizuno J, Nakagawa $H$, Inoue $T$, Hashizume $Y$. Ligamentum flavum hematoma in the lumbar spine: case report. Neurol Med Chir. 2005;45(11):212-215.

5. Taha H, Bareksei Y, Albanna W, Schirmer M. Ligamentum flavum cyst in the lumbar spine: a case report and review of the literature. J Orthop Traumatol. 2010;11(2):117-122.

6. Mahallati H, Wallace CJ, Hunter KM, Bilbao JM, Clark AW. MR imaging of a hemorrhagic and granulomatous cyst of the ligamentum flavum with pathologic correlation. Am J Neuroradiol. 1999;20(6):1166-1168.

7. Ghent F, Ye X, Yan M, Mobbs RJ. A contrastenhancing lumbar ligamentum flavum haematoma. BMJ Case Rep. 2014. https://doi.org/10.1136/bcr-2013-202521

8. Takahashi H, Wada A, Yokoyama Y, Fukushi S, Sakurai T, Shibuya K, Suguro T. Ligamentum flavum haematoma: a report of two cases. J. Orthop Surg. 2009;17(2):212-215.

9. Hsieh CT, Chang CJ, Chang KC. Ligamentum flavum hematoma in the lumbar spine mimicking epidural tumor: a case report. Neurol Asia. 2015;20(3):309-311.

10. Ohba T, Ebata S, Ando T, Ichikawa J, Clinton D, Haro 
H. Lumbar ligamentum flavum hematoma treated with endoscopy. Orthopedics. 2011;34(7):324-327.

11. Mochizuki Y, Miyamoto M, Gembun Y, et al. Ligamentum flavum hematoma in the lumbar spine: a report of three cases and review of the literature. J Orthop. 2011;8(4):e11.

12. Kotil K, Bilge T. A ligamentum flavum hematoma presenting as an L5 radiculopathy. J Clin Neurosci. 2007;14(10):994-997.

13. Yamaguchi S, Hida K, Akino M, Seki T, Yano S, Iwasaki Y. Ligamentum flavum hematoma in the lumbar spine. Neurol Med Chir. 2005;45(5):272-276.

14. Chi TWC, Li KT,Chieng PU. Post-traumatic ligamentum flavum hematoma: a case report. Kaohsiung J Med Sci. 2004;20(1):41-43.
Corresponding Author: Seyed Ahmad Naseri Alavi, MD, Department of Neurosurgery, Faculty of Medicine, Tabriz University of Medical Sciences, Tabriz, Iran, Phone: 0098 9116137353; Email: dr. arsalan2010@gmail.com.

Published 15 August 2018

This manuscript is generously published free of charge by ISASS, the International Society for the Advancement of Spine Surgery. Copyright (c) 2018 ISASS. To see more or order reprints or permissions, see http://ijssurgery.com. 